\title{
Research Article \\ Effect of Bentonite on the Pelleting Properties of Iron Concentrate
}

\author{
Hao Liu, ${ }^{1,2}$ Bing Xie, ${ }^{1}$ and Yue-lin Qin ${ }^{2}$ \\ ${ }^{1}$ College of Materials Science and Engineering, Chongqing University, Chongqing 400044, China \\ ${ }^{2}$ School of Metallurgy and Materials Engineering, Chongqing University of Science and Technology, Chongqing 401331, China
}

Correspondence should be addressed to Yue-lin Qin; qinyuelin710@163.com

Received 13 March 2017; Accepted 29 May 2017; Published 22 June 2017

Academic Editor: María D. Alba

Copyright (C) 2017 Hao Liu et al. This is an open access article distributed under the Creative Commons Attribution License, which permits unrestricted use, distribution, and reproduction in any medium, provided the original work is properly cited.

The physical and chemical properties such as particle size, montmorillonite content, swelling degree, water absorption, and blue absorption of $\mathrm{A}, \mathrm{B}$, and $\mathrm{C}$ bentonites were studied under laboratory conditions. The effects of adding different quality and different proportion of bentonite on falling strength, compression strength, and shock temperature of green pellet were investigated. The experimental results show that the montmorillonite content, water absorption, and methylene blue absorption of bentonite- $\mathrm{B}$ are the highest. And the quality of bentonite- $\mathrm{B}$ is the best, followed by bentonite- $\mathrm{C}$ and bentonite-A poor quality. When the amount of bentonite- $\mathrm{B}$ reduced from $1.5 \%$ to $1.0 \%$, the strength of green pellets and the shock temperature both decrease. As the same proportion of $\mathrm{A}, \mathrm{B}$, and $\mathrm{C}$ bentonites, the green-ball strength and shock temperature are as follows: bentonite- $\mathrm{A}>$ bentonite- $\mathrm{B}>$ bentonite-C.

\section{Introduction}

Pellets should have the properties of high grade, good intensity, and uniform granularity as beneficial furnace burden in the ironmaking process. To increase yield and reduce coke consumption and to improve economic benefits, acidic pellet can be combined with highly basic pellet to form appropriate burden structure [1]. Pellet production has developed significantly as the appropriate burden design of "high basicity sinter + acidic pellet" has become widely adopted throughout the country.

Bentonite is a traditional metallurgical pellet binder, which ensures that the dry and roasted pellets have certain strength properties that meet transportation requirements [2]. Bentonite is a hydrated clay mineral with montmorillonite as its main constituent. The chemical structure of montmorillonite is $\left(\mathrm{Al}_{2}, \mathrm{Mg}_{3}\right)\left(\mathrm{Si}_{4} \mathrm{O}_{10}\right)(\mathrm{OH})_{2} \cdot n \mathrm{H}_{2} \mathrm{O}$. Montmorillonite also contains small amounts of illite, kaolinite, halloysite, chlorite, zeolite, quartz, feldspar, and calcite. Bentonite is either white or yellowish in color and has a wax-like, soil-like, or grease-like luster that depends on iron content. Bentonite can be classified as Na-bentonite, natural bleaching earth, and Ca-bentonite on the basis of exchangeable cation type and content, as well as the size of the montmorillonite layer charge.

Bentonite has strong hygroscopicity and expansibility. It can absorb water by as much as $8-15$ times its dry mass. When wet, it can expand by even up to 30 -fold of its dry mass. Bentonite can be dispersed in aqueous medium as a viscous and suspended material. Bentonite solutions have viscous, variable, and lubricant properties. Different types of bentonites influence pellet properties, as well as the interaction among heterogeneous or homogeneous bentonites and iron concentrate [3-6]. In this study, we utilized three different types of bentonites for a pelletizing test. We investigated the effects of different granularity, components, and content of bentonite on the falling strength, compression strength, and shock temperature on the produced green pellet. The results of this study will provide an experimental basis for the industrial production of bentonite pellets.

\section{Experimental}

2.1. Materials. Iron concentrates and bentonites produced by an iron and steel company in southwest China were used. The main chemical constituents of the iron concentrate and the 
TABLE 1: Physical and chemical analysis of the iron concentrate (\%).

\begin{tabular}{lcccccccccc}
\hline Constituents & $\mathrm{TFe}$ & $\mathrm{SiO}_{2}$ & $\mathrm{Al}_{2} \mathrm{O}_{3}$ & $\mathrm{CaO}$ & $\mathrm{TiO}_{2}$ & $\mathrm{MgO}$ & $\mathrm{FeO}$ & $\mathrm{S}$ & $-0.074 \mathrm{~mm}$ & $\mathrm{Moisture}$ \\
\hline Content & 57.57 & 5.93 & 1.20 & 1.10 & 1.80 & 4.80 & 19.78 & 0.413 & 73.28 & 4.5 \\
\hline
\end{tabular}

TABLE 2: Chemical analysis of the bentonites (\%).

\begin{tabular}{lccccccccc}
\hline Constituents & $\mathrm{MgO}$ & $\mathrm{CaO}$ & $\mathrm{Al}_{2} \mathrm{O}_{3}$ & $\mathrm{P}_{2} \mathrm{O}_{5}$ & $\mathrm{SiO}_{2}$ & $\mathrm{Fe}_{2} \mathrm{O}_{3}$ & $\mathrm{~K}_{2} \mathrm{O}$ & $\mathrm{Na}_{2} \mathrm{O}$ & $\mathrm{MnO}_{2}$ \\
\hline Bentonite- & 4.10 & 2.83 & 13.80 & 0.034 & 61.68 & 2.41 & 0.830 & 0.156 & 0.014 \\
Bentonite- $\mathrm{B}$ & 3.58 & 3.34 & 15.93 & 0.040 & 71.12 & 1.97 & 0.527 & 1.070 & 0.020 \\
Bentonite-C & 3.49 & 1.96 & 14.66 & 0.010 & 63.64 & 1.38 & 0.751 & 0.465 & 0.050 \\
\hline
\end{tabular}

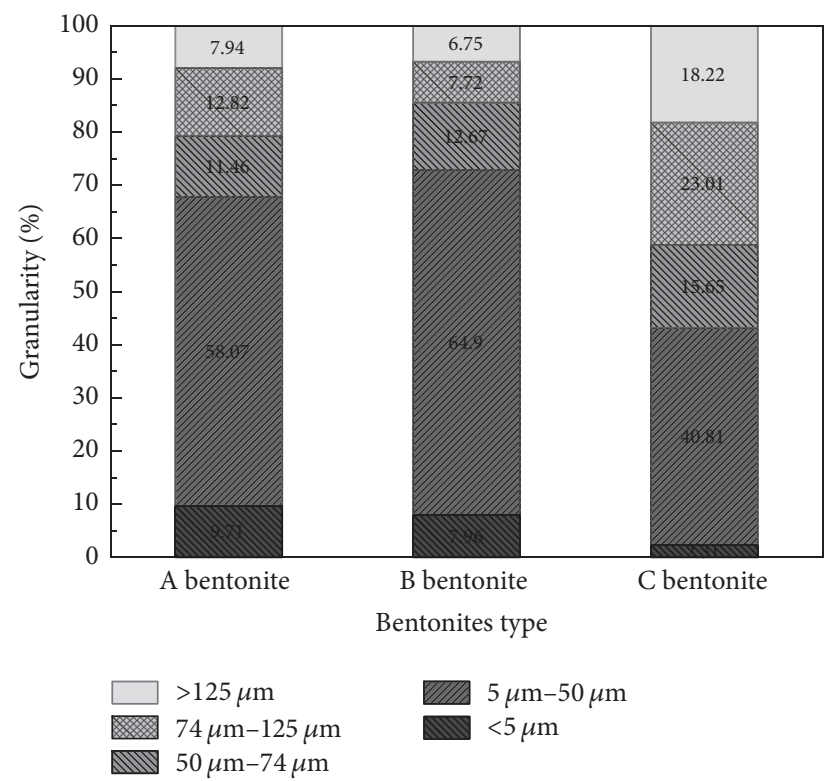

FIgURE 1: Size distribution of bentonite.

bentonites were analyzed by X-ray Fluorescence (XRF). Both the granularity and moisture content of the iron concentrate were also determined. The results are presented in Tables 1 and 2 . The granularity of three different bentonites types A, B, and $\mathrm{C}$ were analyzed and determined by Winner 3002 particle size analyzer, and it is a laser diffraction instrument. The bentonite was analyzed as a dry powder, and it was ground, as shown in Figure 1.

As indicated in Figure 1, the particle size distribution of bentonite types $\mathrm{A}, \mathrm{B}$, and $\mathrm{C}$ was mainly concentrated in the $5-50 \mu \mathrm{m}$ range at $58.07 \%, 64.90 \%$, and $40.81 \%$, respectively. Type B bentonite had the smallest particle size, followed by type A. Type $\mathrm{C}$ bentonite had the largest particle size and the most even particle distribution. Figure 2 shows the full size distribution of the iron ore concentrate.

2.2. Experimental Method. The parameters that represent bentonite properties include colloid value, degree of swelling, water absorption, methylene blue absorption, and montmorillonite content. (1) Colloid value, or colloid content or colloid degree, indicates the montmorillonite content of

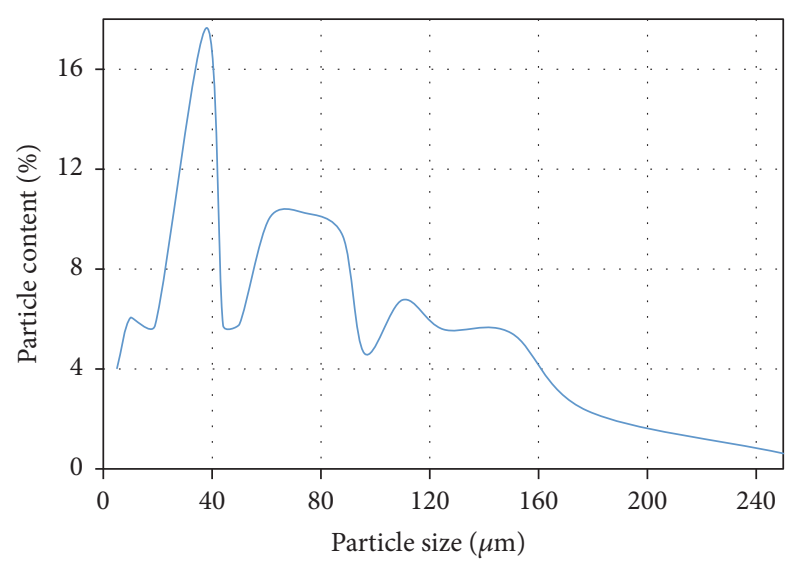

FIGURE 2: The full size distribution of the iron ore concentrate.

bentonite. Colloid value is expressed by the total volume percentage of colloidal mixture in a sample to a certain proportion of water after standing for 24 hours. (2) Expansion factor, or degree of expansion, is related to the dispersion ability of bentonite in water. (3) Methylene blue absorption refers to the grams of methylene blue absorbed by $100 \mathrm{~g}$ bentonite in water. (4) Montmorillonite content is measured on the basis of the absorption of methylene blue by montmorillonite. Metallurgical bentonite quality standard of China (GB/T20973-2007) is adopted in the process of experiment to test and determine the main property of the bentonite.

This study utilized a disc pelletizer with $45^{\circ}$ incline and $1 \mathrm{~m}$ diameter to conduct the pelletizing experiment. The pelletizing process consists of three stages: (1) mixing of the raw material to produce the raw pellet, (2) pellet enlargement, and (3) pellet hardening. During the pelletizing, the atomized water was added in the area of disc pelletizer. The water was deionized to avoid the effects of water chemistry on pelletization performance. The total weight of raw material was $4 \mathrm{~kg}$. During the first stage, which occurred for $3 \mathrm{~min}$, raw pellets were produced from $1 \mathrm{~kg}$ of raw material. After 9 min, more raw material was added to enlarge the raw pellets. During the last stage, the enlarged pellet was hardened for $3 \mathrm{~min}$. The total time of pelletizing process was $15 \mathrm{~min}$. Afterwards, the green pellets were removed and continually sprayed with water to maintain moisture content at $7.0 \pm 0.5 \%$. 


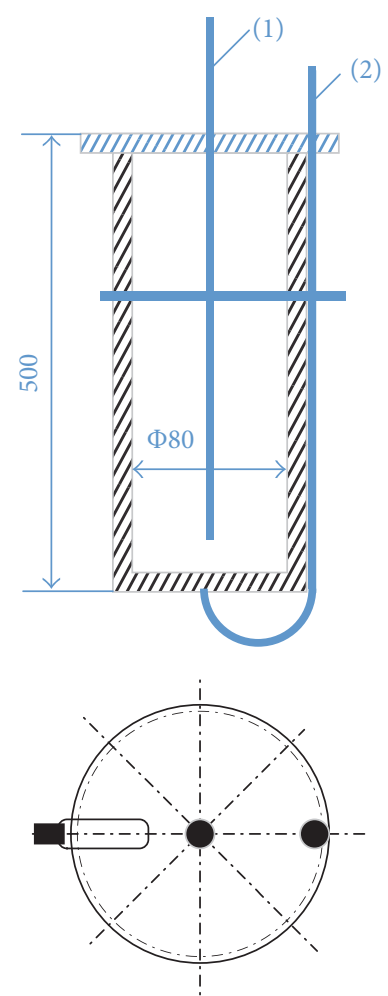

(1) Thermocouple

(2) Compressed air into the pipe

FIgURE 3: Burst temperature measuring device.

The dry configuration proportions were $1.5 \%$ (bentonite- $\mathrm{A}$ ), $1.5 \%$ (bentonite- $\mathrm{B}$ ), $1.3 \%$ (bentonite- $\mathrm{C}$ ), $1.0 \%$ (bentonite- $\mathrm{B}$ ), and $1.0 \%$ (bentonite-C).

Green pellet properties include compression strength, moisture content, falling strength, and shock temperature. (1) To test compression strength, the green pellet was placed on an electronic scale and pressed at constant speed until the green pellet broke. The pressure value was recorded when the pellet broke. The same process was repeated 10 times, and the recorded pressure values were averaged over the 10 repeats. (2) To test the moisture content, the green pellet was pulverized. Then, a $20-25 \mathrm{~g}$ sample was placed in a rapid moisture measuring instrument to measure and record the value of moisture content. The same process was repeated thrice. The moisture content value was averaged over the three attempts. (3) To test falling strength, the green pellet was dropped from a height of $0.5 \mathrm{~m}$ until the ball broke for certain number of times. The test was repeated 10 times. Falling strength values were averaged over the 10 attempts. (4) Shock temperature was assessed with the Dynamic Method developed by AC Company, USA (Figure 3). The shock temperature test was conducted in the special vertical tube furnace. Ambient-temperature air was sent from an air compressor into the tube furnace at a speed controlled by a rotary flowmeter. The tube furnace was equipped with a silicon carbide bar. Its temperature was controlled by an automatic silicon temperature controller. A $\varphi 80 \times 500 \mathrm{~mm}$

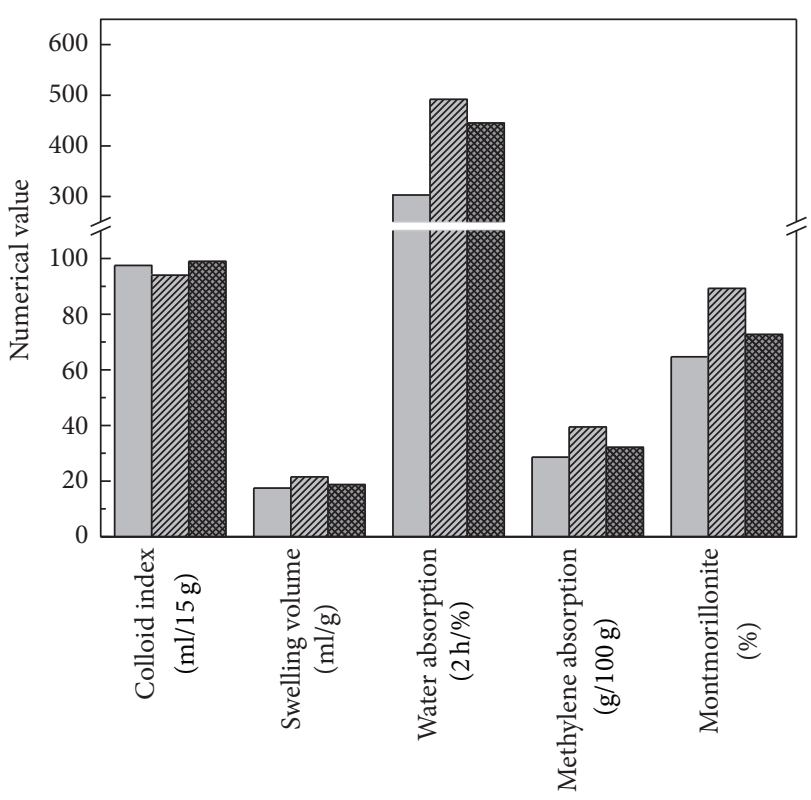

Properties of bentonites

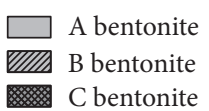

FIGURE 4: Results of bentonite pellet test.

stainless steel hot air blast pipe, which contained a $\varphi 10 \mathrm{~mm}$ alumina ball $200 \mathrm{~mm}$ in height, was installed in the device. The electric furnace heated the alumina ball, which instantly heated up the air from the compressor. The thermocouple for real-time detection of the hot air temperature was inserted in a hole from the top of the furnace. As illustrated in Figure 3, the drying container used to collect the green pellet had a heat-resistant nickel chromium wire frame, an inner diameter of $50 \mathrm{~mm}$, and a height of $120 \mathrm{~mm}$. Thus, air flow can easily pass through the green pellet layer. Then, 25 green pellets were loaded into the nickel chromium wire frame and hoisted into the reaction drum from the top of the drum. The air speed inside the drum was $1.5 \mathrm{~m} / \mathrm{s}$ under cold conditions. After 3 minutes, the green pellets were removed. The highest temperature required to break $4 \%$ of the green pellets was recorded as the shock temperature.

\section{Results and Discussion}

3.1. Physical and Chemical Properties of Bentonite. Figure 4 illustrates the properties of the three bentonite types utilized by this experiment. The montmorillonite content of type $\mathrm{B}$ bentonite is $89.25 \%$, which is higher than those of type A (64.7\%) and type C (72.74\%). Type B has the highest values for swelling volume, water absorption, and methylene blue absorption, followed by type $\mathrm{C}$ and type $\mathrm{A}$. Montmorillonite absorbs methylene blue when bentonite is dispersed in water. Hence, bentonite with a high montmorillonite content absorbs more methylene blue. Methylene blue absorption is also an indicator for absorptivity and water absorption 
TABLE 3: Effect of bentonite type on the pellet index.

\begin{tabular}{|c|c|c|c|c|c|c|}
\hline $\begin{array}{l}\text { Exp. } \\
\text { number }\end{array}$ & $\begin{array}{l}\text { Moisture } \\
\text { content } / \% \\
\end{array}$ & $\begin{array}{c}\text { Falling } \\
\text { strength/times-pellet }^{-1}\end{array}$ & $\begin{array}{c}\text { Compression } \\
\text { strength/N.pellet } \\
\end{array}$ & Shock temperature $/{ }^{\circ} \mathrm{C}$ & $\begin{array}{l}\text { Bentonite } \\
\text { content } / \%\end{array}$ & $\begin{array}{l}\text { Weight of qualified } \\
\text { pellets }(>10 \mathrm{~mm}) / \mathrm{kg}\end{array}$ \\
\hline 1 & 7.28 & $2.53 \pm 0.01$ & $9.02 \pm 0.02$ & $550 \pm 3$ & $1.5(\mathrm{~A})$ & 0.94 \\
\hline 2 & 6.79 & $3.00 \pm 0.02$ & $9.76 \pm 0.03$ & $550 \pm 2$ & $1.5(\mathrm{~B})$ & 1.43 \\
\hline 3 & 6.64 & $2.60 \pm 0.01$ & $9.42 \pm 0.02$ & $550 \pm 2$ & $1.3(\mathrm{~B})$ & 0.50 \\
\hline 4 & 7.46 & $2.53 \pm 0.02$ & $8.23 \pm 0.02$ & $500 \pm 3$ & $1.0(\mathrm{~B})$ & 0.67 \\
\hline 5 & 7.13 & $2.07 \pm 0.02$ & $7.97 \pm 0.02$ & $500 \pm 2$ & $1.0(\mathrm{C})$ & 1.41 \\
\hline
\end{tabular}

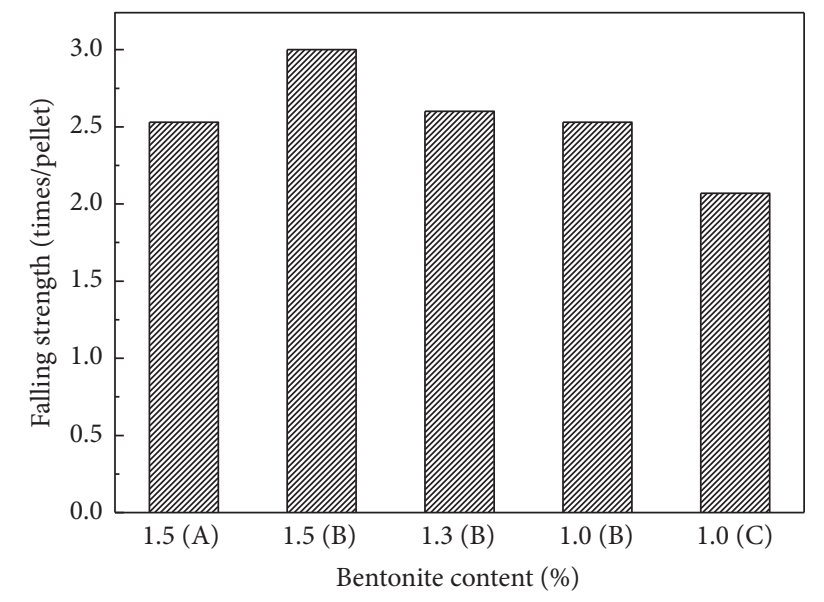

FIGURE 5: Effect of different types and proportions of bentonite on the falling strength of the ball.

[3]. A higher methylene blue absorption value indicates that the bentonite has higher absorptivity, water absorption capacity, and larger swelling volume. Methylene blue absorption, swelling volume, montmorillonite content, and water absorption are important indices for evaluating bentonite quality. Therefore, type B bentonite has the highest quality, followed by type $\mathrm{C}$ and finally type $\mathrm{A}$.

\subsection{Effect of Different Types and Content of Bentonite on the} Properties of Green Pellets. Table 3 present the properties of green pellets that contain different types and proportions of bentonites. Type A and type B bentonite content is set at 1.5\% in experiments 1 and 2 . Bentonite- $\mathrm{B}$ content is set at $1.3 \%$ in experiments 3. Type B and bentonite- $\mathrm{B}$ and bentonite- $\mathrm{A}$ content is set at $1.0 \%$ in experiments 4 and 5 .

Figure 5 shows the effect of different types and proportions of bentonite on the falling strength of the green pellet. When bentonite content is $1.5 \%$ and $1.3 \%$, the falling strength of the green pellet improved compared with those of green pellets that contain $1.0 \%$ bentonite. Increasing homogeneous bentonite content from $1.5 \%$ to $1.0 \%$ gradually decreases the falling strength from 3.00 times/pellet to 2.53 times/pellet. When the bentonite content is $1.5 \%$, the falling strength of the green pellets of type $B$ is better than that of the green pellets of type A. When the bentonite content is $1.0 \%$, the falling strength of green pellets of type B is better than that of green pellets of type $C$. The falling strength of the three different

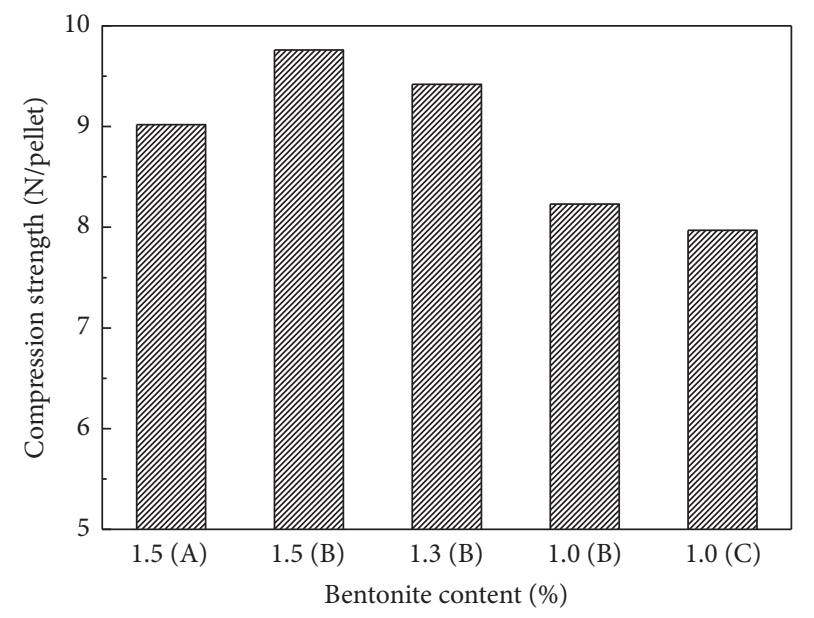

FIGURE 6: Effect of different types and proportions of bentonite on the compression strength of the ball.

types of bentonites decreases in the following order: type $\mathrm{B}>$ type $\mathrm{C}>$ type $\mathrm{A}$.

Figure 6 presents the effect of different types and proportions of bentonite on the compression strength of the green pellet. With increasing homogeneous bentonite content from $1.5 \%$ to $1.0 \%$, the compression strength decreases from $9.76 \mathrm{~N} /$ pellet to $8.23 \mathrm{~N} /$ pellet. When bentonite contents are $1.5 \%$ and $1.3 \%$, the compression strength of the green pellet improved compared with those of green pellets that contain $1.0 \%$ bentonite. When the bentonite content is $1.5 \%$, the compression strength of the green pellets of type B is better than that of the green pellets of type A. When the bentonite content is $1.0 \%$, the compression strength of green pellets of type $B$ is better than that of green pellets of type C. The compression strength of the three different types of bentonites decreases in the following order: type $\mathrm{B}>$ type $\mathrm{C}$ $>$ type A.

Figure 7 shows that when the bentonite contents are $1.5 \%$ and $1.3 \%$, the shock temperature of the pellet is $823 \mathrm{~K}$, compared with the $773 \mathrm{~K}$ shock temperature of the pellet with $1.0 \%$ added bentonite. The pellet explodes during the drying process because moisture transfers towards loosely structured areas of the pellet, which increases internal pressure. The pellet explodes when the internal pressure exceeds the pellet's tensile strength. Given that bentonite has a greater capacity for water absorption, the crystal layers of bentonite can firmly absorb moisture onto the surface 


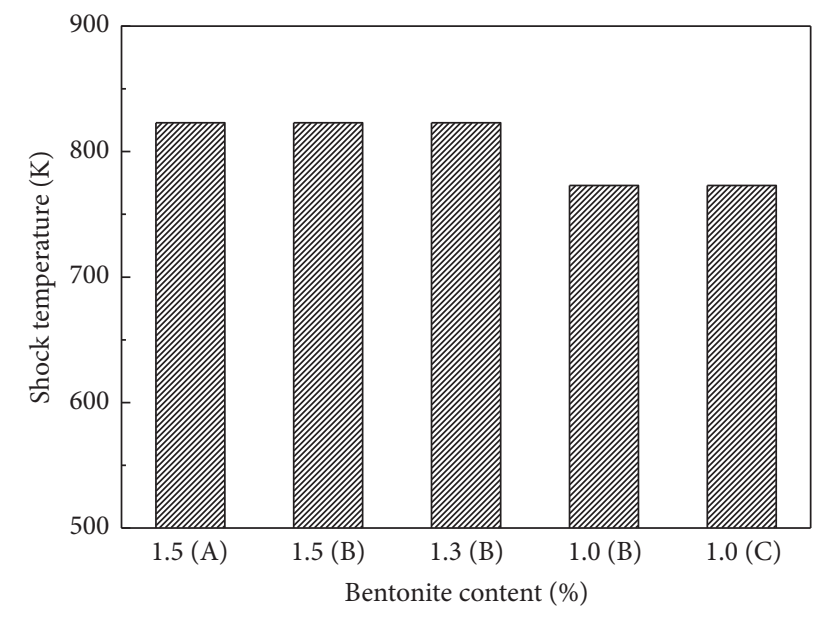

FIGURE 7: Effect of different types and proportions of bentonite on the shock temperature of the ball.

of montmorillonite because of the effect of negative field force. Therefore, free water does not easily evaporate and transfer. During the drying and evaporation process, the water absorption property of bentonite slows down water evaporation from the pellet. Thus, moisture is released slowly from the pellet, which reduces the internal steam pressure and increases the shock temperature of the pellet [7-10]. Therefore, increasing bentonite content increases the shock temperature of the pellet.

The results indicate that the quality of the three different types of bentonites decreases in the following order: type $\mathrm{B}>$ type $\mathrm{C}>$ type $\mathrm{A}$. Therefore, at a constant content of heterogeneous bentonites, falling strength and compression strength are dependent on bentonite quality because bentonite particles are fine with a specific surface area of $100 \mathrm{~m}^{2} / \mathrm{g}$. Hence, the dispersion property of bentonite is not only acceptable, but its water absorption and expansion properties also enable fine particles to fill and absorb between the ore particles. The nature of the ore surface changes accordingly to form microcapillaries when a solid bridge and liquid bridge are added. When capillary force increases, the compression strength of the green pellet also improves [11]. Montmorillonite content dictates the physicochemical properties of bentonite and montmorillonite arranges into structured layers of aqueous aluminum silicate with expansion property [7, 12]. Bentonite begins to swell upon absorbing water. Under mechanical shear stress, the swollen bentonite can improve the relative sliding between the ore particles via plastic deformation [13, 14]. Therefore, bentonite is not easily broken and the falling strength of the green pellet is enhanced.

\section{Conclusion}

This study investigated the influence of type and proportion of bentonite on falling strength, compression strength, and shock temperature of green pellets by adding bentonite of different types and proportions to iron concentrates. The following conclusions were made:
(1) Montmorillonite content is directly correlated with the degree of swelling, water absorption, and methylene blue absorption of bentonite. The degree of swelling, water absorption, and ethylene blue absorption increase as montmorillonite content increases. These characteristics indicate the good quality of bentonite.

(2) Adding bentonite improves the strength of the green pellet. The falling strength and compression strength of green pellet increase as bentonite content increases. For homogeneous bentonites, the strength of the green pellet increases as bentonite content increases. For heterogeneous bentonites, the strength of green pellet depends on the quality of bentonite at a constant bentonite content.

(3) Adding a higher proportion of high-quality bentonite to the iron concentrates increases the bursting temperature resistance of the green pellet.

\section{Conflicts of Interest}

The authors declare that there are no conflicts of interest regarding the publication of this paper.

\section{Acknowledgments}

The authors would like to acknowledge the National Natural Science Foundation of China (no. 51604054), Scientific and Technological Research Program of Chongqing Municipal Education Commission (nos. KJ1501307 and KJ1601331), and Chongqing Research Program of Basic Research and Frontier Technology (no. cstc2016jcyjA0647).

\section{References}

[1] X. B. Zhang, "Effect of bentonite additive on pelletizing operation of our country," Sintered pellets, vol. 28, no. 6, pp. 3-6, 2003.

[2] X. B. Zhang, "Discussion on performance index of bentonite used for metallurgical pelletizing," Sintered pellets, vol. 35, no. 4, pp. 12-16, 2010.

[3] Y. Z. Zhang, "Influence of bentonite properties on pellet performances," Sintered pellets, vol. 31, no. 2, pp. 4-21, 2006.

[4] Y. R. Li, M. S. Zhou, L. W. Zhai, L. G. Zhang, and W. Ren, "Effect of types of bentonites on green pellet propert," Anshan Iron and Steel Technology, vol. 3, no. 1, pp. 15-19, 2009.

[5] Z. C. Huang, Y. Jiang, Z. G. Han, and G. X. Huang, "Study on the mechanism of using bentoni te as binder in spheric agglomeration of iron ores," Chemical Minerals and Processing, vol. 8, no. 1, pp. 13-15, 2005.

[6] Z. Y. Lv, M. S. Shen, and W. G. Kang, "Experimental research on restraining reduced expansion of pellets by adding bentonite," Baotou Steel Technology, vol. 37, no. 4, pp. 33-35, 2011.

[7] B. Alince, F. Bednar, and T. G. M. Van de Ven, "Deposition of calcium carbonate particles on fiber surfaces induced by cationic polyelectrolyte and bentonite," Colloids and Surfaces A: Physicochemical and Engineering Aspects, vol. 190, no. 1-2, pp. 71-80, 2001. 
[8] T. C. Eisele and S. K. kawatra, "A review of of binders in iron ore palletization," Minerals Processing and Extractive Metallurgy Review, vol. 24, no. 1, pp. 1-47, 2003.

[9] Y. M. Zhang, Pellet theory and technology, Metallurgical Industry Press, Beijing, China, 2008.

[10] Z. L. Xue, "Study on the shock temperature of iron ore green pellets," Journal of Wuhan Iron and Steel Institute, vol. 15, no. 3, pp. 249-255, 1992.

[11] H. Q. Zhang, "Application of bentonite in iron ore oxidation pellets," China Mining, vol. 18, no. 8, pp. 99-102, 2009.

[12] S. K. Kawatra and S. J. Ripke, "Effects of bentonite fiber formation in iron ore pelletization," International Journal of Mineral Processing, vol. 65, no. 3-4, pp. 141-149, 2002.

[13] C. X. Li, R. C. Ren, and M. Y. Liao, "Study on binder of bentonite from western Liaoning for iron pellet," Non-metallic mineral, vol. 32, no. 3, pp. 42-46, 2009.

[14] H. M. Feng and Y. H. Wang, "Explore mechanism of benonite in iron ore pelletting," China Non-metallic Mineral Industry Guide, vol. 6, no. 1, pp. 15-18, 2009. 

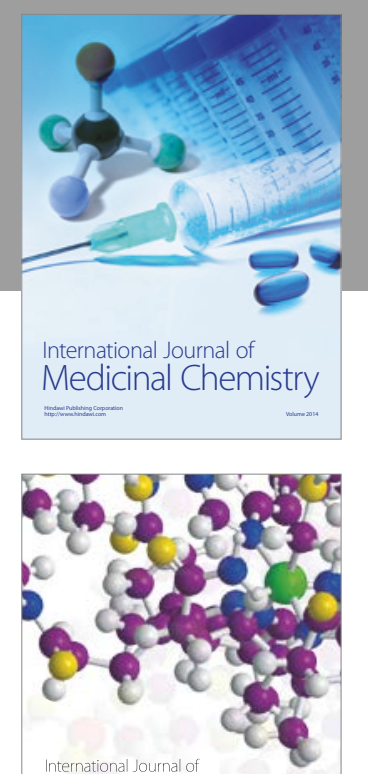

Carbohydrate Chemistry

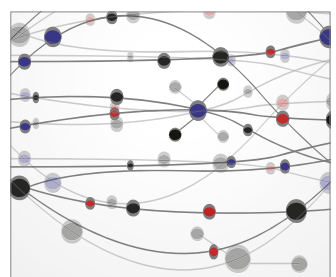

The Scientific World Journal
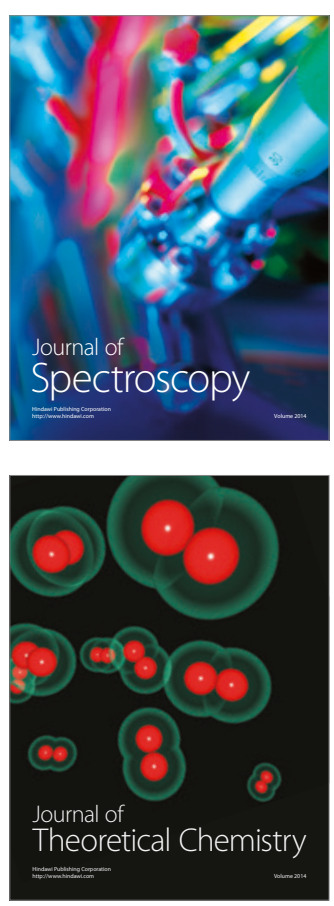
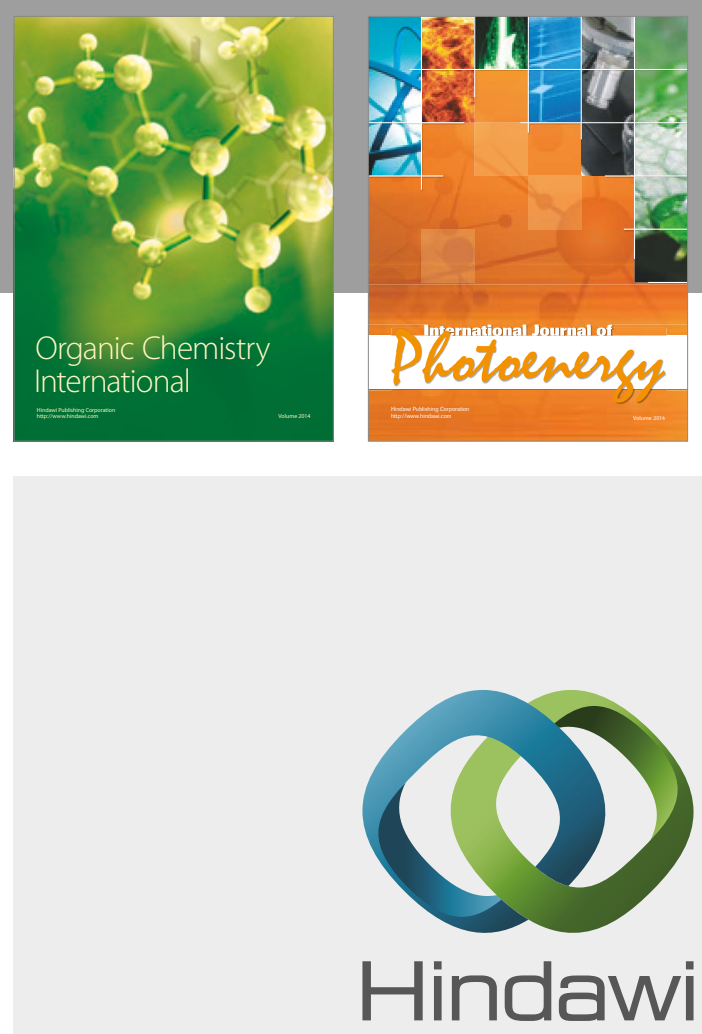

Submit your manuscripts at

https://www.hindawi.com

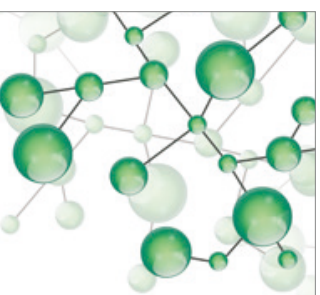

International Journal of

Inorganic Chemistry

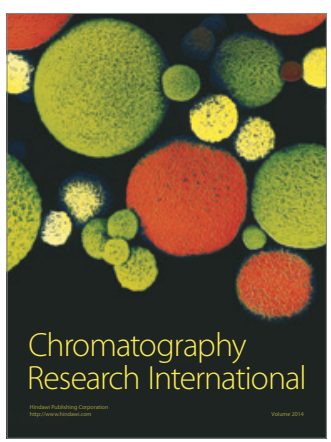

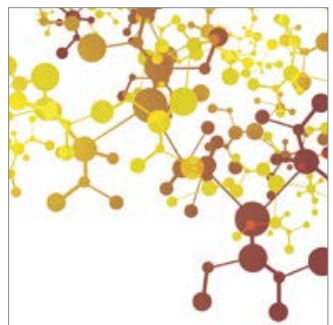

Applied Chemistry
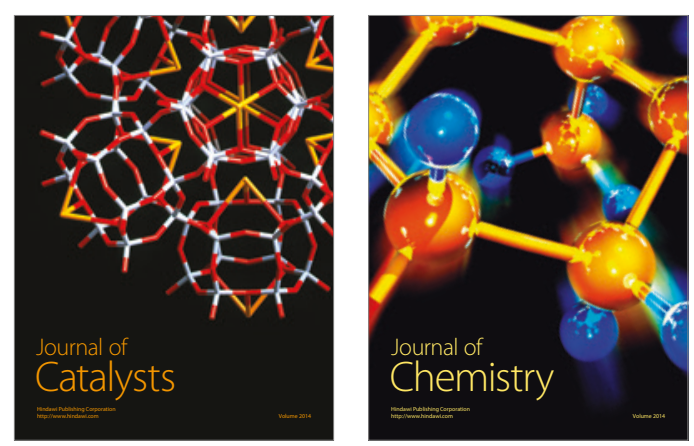
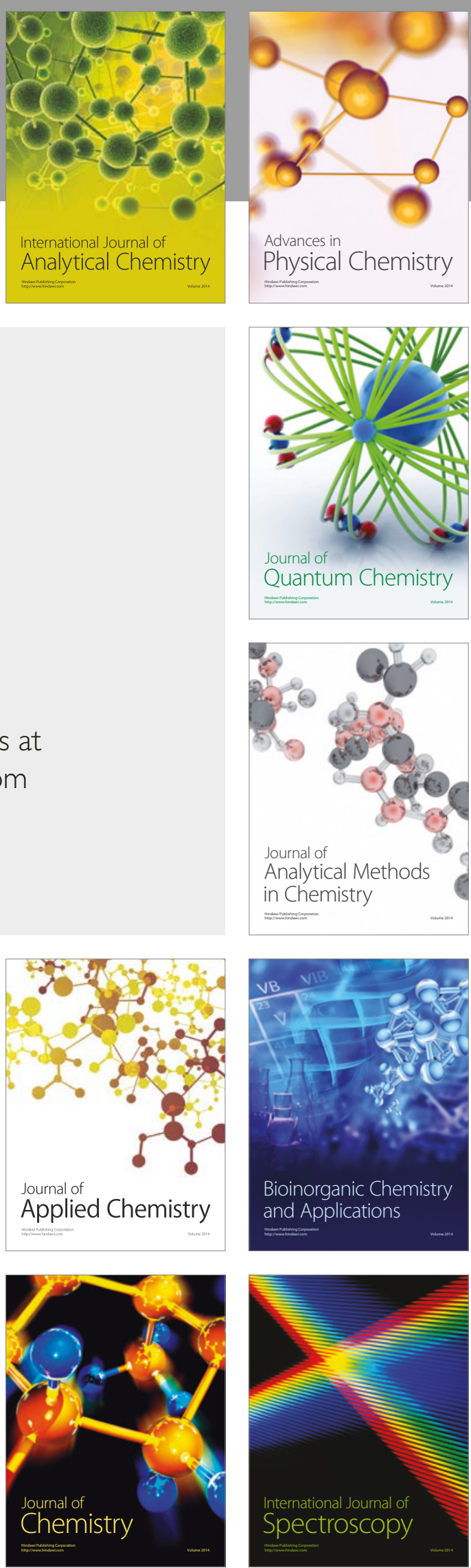